\title{
Wimpern plötzlich weiß: an Partydrogen denken!
}

Schneeweiße Wimpern und Augenbrauen, eine ausgedehnte, schuppende Dermatitis und Mees-Streifen an den Nägeln: Nicht eine Thalliumvergiftung war schuld an diesen auffälligen Symptomen der drei jungen Männer. Als Ursache entpuppte sich vielmehr die toxische Wirkung einer Partydroge.

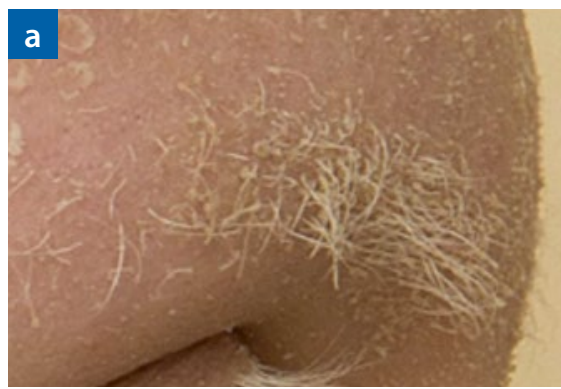

Folgen des Drogenkonsums: a: Haardepigmentierung und Haarverlust, b: Mees-Streifen auf den Fingennägeln

$\mathrm{D}$ ie drei jungen Männer, die sich unabhängig voneinander zwischen Herbst 2013 und Sommer 2014 in schwedischen Arztpraxen präsentierten, zeigten eine außergewöhnliche Symptomenpalette, die sich in allen drei Fällen auf frappierende Weise ähnelte: Die Patienten berichteten, ihre Haare (am Kopf) seien innerhalb kurzer Zeit immer dünner geworden und hätten an Farbe verloren. Bei einem Mann waren sie komplett ausgefallen. Augenbrauen und Wimpern hatten sich schneeweiß verfärbt (Abb. a). Außerdem klagten die Männer über gereizte, trockene Augen, ein starkes Kältegefühl, trockene Haut und großflächige Ausschläge, insbesondere am Rücken, aber auch in der Achsel- und Leistengegend sowie an den Beinen.

Bei näherer Untersuchung der Patienten fanden sich scharf abgegrenzte, erythematöse Hautareale, die teilweise von großen weißen Schuppen bedeckt waren, ähnlich wie bei der Ichthyose. Eine Follikulitis mit ausgeprägter $\mathrm{Pa}$ pel- und Pustelbildung erstreckte sich über die schuppenden Areale hinaus. Die Dermatitis war zwar schmerzhaft, juckte aber kaum. Einer der Patienten hatte deutliche Fissuren an den Fußsohlen. Zwei Patienten zeigten außerdem Mees-Streifen: quer verlaufende weiße Linien auf den Finger- und $\mathrm{Ze}$ hennägeln (Abb. b).

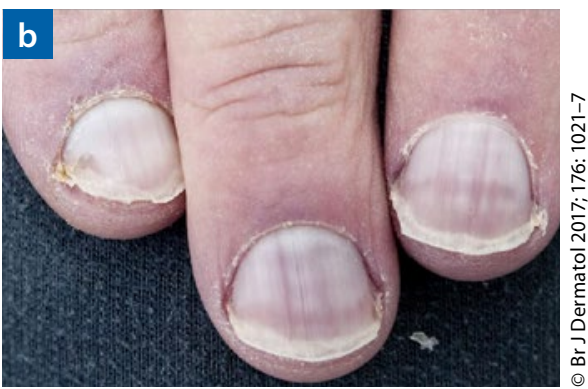

lassen worden war. Die Substanz ist nur ein Vertreter der mittlerweile massenhaft - vor allem im Internet - angebotenen "legal highs“: psychoaktive Substanzen, welche in geheimer Produktion hergestellt und, um Kontrollen zu umgehen, „maskiert", also beispielsweise als Badesalze zur äußerlichen Anwendung, vermarktet werden.

Teilweise zeichnen sich die Substanzen durch erhebliche Toxizität aus. Im Falle des MT- 45 betraf diese vor allem die Haut, Haarfollikel und, wie sich erst später herausstellte, auch die Augenlinse. Die Linse stammt embryogenetisch aus demselben Keimblatt wie Haut und Appendices, nämlich aus dem Ektoderm.

Tatsächlich hätte der Konsum der Partydroge zwei Männern fast das Augenlicht gekostet: Gut ein Jahr nach der Erstvorstellung bildete sich jeweils auf beiden Augen eine rasch progrediente Katarakt. Diese konnte letztlich in beiden Fällen noch rechtzeitig operiert werden.

Fazit: Bei ungewöhnlichen und unerklärlichen Symptomen an Haaren, Haut, Nägeln und Augen sollte der Dermatologe an die Einnahme psychoaktiver Substanzen denken und entsprechende Tests veranlassen.

Dr. Elke Oberhofer zogen. Die daraufhin angefertigten Bluttests zeigten hohe Konzentrationen der Designerdroge MT-45. Dabei handelt es sich um ein Piperazin-Derivat, welches ursprünglich als Analgetikum entwickelt, dann aber wegen unvorhergesehener Toxizität nie als Arznei zuge-

Helander A et al. Acute skin and hair symptoms followed by severe, delayed eye complications in subjects using the synthetic opioid MT-45.

Br J Dermatol 2017; 176: 1021-7

\author{
Erratum \\ Erratum zu: Aktinische Keratose: mit Photolyase neuen Läsionen besser vorbeugen \\ Dagmar Kraus \\ Erratum zu: hautnah dermatologie 2017; 33 (1): 20
}

In Ausgabe 1/2017 S. 20 haben wir die Studie von Eibenschutz L et al. Br J Dermatol 2016; 175: 1391-3 besprochen („Aktinische Keratose: mit Photolyase neuen Läsionen besser vorbeugen“). Dort ist fälschlicherweise die Rede davon, das Vergleichspräparat sei „Avène Sonnencreme 50+, Laboratoires Dermatologiques Paris, Frankreich". Tatsächlich handelte es sich bei der verwendeten Kontrolle um „Fotoprotector, ISDIN, Barcelona, Spain“. Wir bitten um Berücksichtigung.

Die Redaktion

Die Online-Version des Originalartikels ist unter doi: 10.1007/s15012-017-2323-z zu finden. 